\section{Correspondence on 'Blood-brain barrier leakage in systemic lupus erythematosus is associated with gray matter loss and cognitive impairment'}

We read the article by Kamintsky et $a l^{1}$ with great interest. The study used dynamic contrast-enhanced MRI to calculate cross Blood-brain barrier (BBB) leakage rates in patients with neuropsychiatric systemic lupus erythematosus (NPSLE). This article reported that patients with SLE had higher BBB leakage compared with controls. Almost a quarter of patients with SLE showed extensive BBB leakage and this SLE group had smaller cerebral grey matter volumes and impaired global cognitive function. The study provided objective evidence of impaired BBB in NPSLE. However, the exact mechanisms resulting in BBB leakage in NPSLE remain elusive. The authors have suggested a role of antiribosomal $\mathrm{P}$ and anti-NR2 antibodies and complement activation products as possible contributing factors to BBB leakage. 23 Also, some non-SLE-related factors, such as smoking, hypertension and systemic infections, can increase BBB permeability. ${ }^{4}$

Here, we want to mention other potential mechanisms to explain higher BBB leakage in NPSLE. The central nervous system (CNS) was previously considered to not have a classical lymphatic drainage system. ${ }^{5}$ However, several studies using tracers injected into cerebrospinal fluid (CSF) revealed lymphatic drainage from CNS into cervical lymph nodes (CLNs). ${ }^{6} 7 \mathrm{~A}$ study using animal models discovered functional lymphatic vessels lining dural sinuses which are connected to deep CLNs and are able to carry fluid and immune cells from CSF. ${ }^{8}$ These discoveries challenged the concept of lack of lymphatic drainage system in the CNS. The immune cells may contribute to neuroinflammation by reaching the brain via lymphatics from deep and superficial lymphatic systems. One study showed that excision of the CNS-draining lymph nodes reduced the CNS inflammation in experimental autoimmune encephalomyelitis. ${ }^{9}$ A recent study using animal models of focal cerebral ischemia revealed that ischaemic stroke triggered activation of lymphatic endothelium in CLNs via vascular endothelial growth factor (VEGF)-C/ VEGF receptor (VEGFR)-3 signalling, while surgical excision of superficial CLNs improved poststroke inflammation and reduced brain injury. ${ }^{7}$ These studies suggest that the lymphatic systemic and CLNs play an important role in CNS inflammation. ${ }^{79}$ In addition, another study in living zebrafish using high-resolution optical imaging of the meninges confirmed a meningeal lymphatic network draining interstitial fluid from the brain. The study also showed that neutrophils could be readily trafficking within this lymphatic vessel lumen. ${ }^{10}$

Studies in lupus prone mice (MRL/MpJ-Fas ${ }^{\text {lpr/pr }}$ ) showed tertiary lymphoid structure formation in the choroid plexus and a site for lymphocyte trafficking into the brain. Increased leucocyte migration via choroid plexus was shown in histological analysis of brain in human NPSLE patients. ${ }^{11}$

We suggest that a dysfunctional CNS lymphatic system and increased immune cell trafficking via CLNs play an important role in the neuroinflammation associated with NPSLE. In addition, it may contribute to impaired BBB by increased production of pro-inflammatory cytokines and complement activation in NPSLE. The exact role of the CNS lymphatic system in neuroinflammation and BBB permeability requires further research to better understand the pathogenesis of NPSLE and finding a potential therapeutic target.
Omer Nuri Pamuk $\odot{ }^{1}$ Sarfaraz Hasni ${ }^{2}$

${ }^{1}$ Rheumatology Fellowship and Training Branch, National Institute of Arthritis and Musculoskeletal and Skin Diseases, National Institutes of Health, Bethesda, Maryland, USA

${ }^{2}$ Lupus Clinical Research Program, Office of the Clinical Director, National Institute of Arthritis and Musculoskeletal and Skin Diseases, National Institutes of Health, Bethesda, Maryland, USA

Correspondence to Dr Omer Nuri Pamuk, NIAMS, National Institutes of Health, Bethesda, Maryland MD 20892, USA; pamukon@nih.gov

Acknowledgements This research was supported by the Intramural Research Programme of the National Institute of Arthritis and Musculoskeletal and Skin Diseases of the National Institutes of Health.

Contributors ONP: concept, writing. SH: concept, revising.

Funding This research was supported by the Intramural Research Programme of the National Institute of Arthritis and Musculoskeletal and Skin Diseases of the National Institutes of Health.

\section{Competing interests None declared.}

Patient and public involvement Patients and/or the public were not involved in the design, or conduct, or reporting or dissemination plans of this research.

Patient consent for publication Not required.

Provenance and peer review Not commissioned; internally peer reviewed.

(C) Author(s) (or their employer(s)) 2021. No commercial re-use. See rights and permissions. Published by BMJ.

\section{Check for updates}

To cite Pamuk ON, Hasni S. Ann Rheum Dis Epub ahead of print: [please include Day Month Year]. doi:10.1136/annrheumdis-2021-220031

Received 28 January 2021

Accepted 30 January 2021

\section{Linked}

- http://dx.doi.org/10.1136/annrheumdis-2021-220057

Ann Rheum Dis 2021;0:1. doi:10.1136/annrheumdis-2021-220031

ORCID iD

Omer Nuri Pamuk http://orcid.org/0000-0001-5377-5879

\section{REFERENCES}

1 Kamintsky L, Beyea SD, Fisk JD, et al. Blood-Brain barrier leakage in systemic lupus erythematosus is associated with gray matter loss and cognitive impairment. Ann Rheum Dis 2020;79:1580-7.

2 Duarte-Delgado NP, Vásquez G, Ortiz-Reyes BL. Blood-Brain barrier disruption and neuroinflammation as pathophysiological mechanisms of the diffuse manifestations of neuropsychiatric systemic lupus erythematosus. Autoimmun Rev 2019;18:426-32.

3 Yoshio T, Okamoto $\mathrm{H}$, Hirohata S, et al. Igg anti-NR2 glutamate receptor autoantibodies from patients with systemic lupus erythematosus activate endothelial cells. Arthritis Rheum 2013;65:457-63.

4 Mazzone P, Tierney W, Hossain M, et al. Pathophysiological impact of cigarette smoke exposure on the cerebrovascular system with a focus on the blood-brain barrier: expanding the awareness of smoking toxicity in an underappreciated area. Int $J$ Environ Res Public Health 2010;7:4111-26.

5 Louveau A, Smirnov I, Keyes TJ, et al. Structural and functional features of central nervous system lymphatic vessels. Nature 2015;523:337-41.

6 Cserr HF, Knopf PM. Cervical lymphatics, the blood-brain barrier and the immunoreactivity of the brain: a new view. Immunol Today 1992;13:507-12.

7 Esposito E, Ahn BJ, Shi J, et al. Brain-to-cervical lymph node signaling after stroke. Nat Commun 2019:10:5306.

8 Louveau A, Herz J, Alme MN, et al. Cns lymphatic drainage and neuroinflammation are regulated by meningeal lymphatic vasculature. Nat Neurosci 2018;21:1380-91.

9 van Zwam M, Huizinga R, Heijmans N, et al. Surgical excision of CNS-draining lymph nodes reduces relapse severity in chronic-relapsing experimental autoimmune encephalomyelitis. J Pathol 2009;217:543-51.

10 Castranova D, Samasa B, Venero Galanternik M, et al. Live imaging of intracranial lymphatics in the zebrafish. Circ Res 2021;128:42-58.

11 Stock AD, Der E, Gelb S, et al. Tertiary lymphoid structures in the choroid plexus in neuropsychiatric lupus. JCI Insight 2019;4:jci.insight.124203. doi:10.1172/jci. insight. 124203 